\title{
To Kin a Transnationally Adopted Child in Norway and Spain: The Achievement of Resemblances and Belonging
}

\section{Signe Howell \& Diana Marre}

University of Oslo, Norway \& University of Barcelona, Spain

ABSTRACT Transnational adoption has become a major means for involuntarily childless people to become a family, and for people who do not want to go through the 'normal' procedures to obtain a child. In this paper we present a comparative analysis of some pertinent features pertaining to the understanding of kinship that arise out of the practice of transnational adoption in Norway and Spain. For a variety of reasons, these two countries have achieved a leading role in the world of transnational adoption in so far as they adopt more children per capita than any other country. This is particularly interesting in light of the very different social and political situation of these two countries. Our focus will be on the concepts employed in the kinning process by adoptive parents and on how they symbolize bodies and personalities in attempts to create meaningful resemblances between themselves and their children.

KEYWORDs Transnational adoption, kinning processes, symbolizing bodies

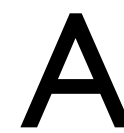
doption of the unrelated child gives rise to debates about the meaning of kinship, not only amongst anthropologists and those who adopt, but also amongst those who are involved in the administration of adoptions. In societies - such as those of Western Europe and North America - where kinship is predicated upon a model of biological connectedness between parents and children, where '[n]ature itself', in the words of M. Strathern, 'provide[s] the very model for domaining' (I992:I77), the debates become particularly intense. In the case of transnational adoption, issues of race, ethnicity and culture further complicate the issues. With empirical material from Norway and Spain, ${ }^{\mathbf{}}$ we shall examine some of the debates. Our focus will be on the ways adoptive parents of children from the Third World and Eastern Europe handle the personal challenges involved in the practice.

ETHNOS, VOL. 7I:3, SEPT. 2006 (PP. 293-3I6)

(C) Routledge Journals, Taylor and Francis, on behalf of the Museum of Ethnography ISSN OOI4-I844 PRINT/ISSN I469-588X ONLINE. DOI: IO.IO80/OOI4I840600902679 
Since the late r96os the number of children adopted from countries in the poor South, and more recently from the former Soviet bloc countries, to prospective parents in the rich North has seen a dramatic increase. More than 40,000 children were adopted by people in Western Europe and North America in 2004, and the demand is steadily rising - not least because Spain and Italy, which previously did not engage in the practice, have started to do so. Today, in terms of transnational adoption per capita, the Autonomous Community of Catalonia in Spain shows the highest rate at 2.3 percent of live births, followed by Spain as a whole and Norway, each with r.6 percent (Selman 2005).

When we examine the statistics for transnational adoption, a clear picture emerges. Not only is the total number of adopted children steadily increasing, but the profile of the countries (both donor and receiving) is changing (Table I and Note 2). ${ }^{2}$

Table I. Numbers of adoptees by major receiving countries in I989, I998, 2003

\begin{tabular}{|c|c|c|c|}
\hline Countries & 1989 & 1998 & 2003 \\
\hline USA & $9, \mathbf{I} 20$ & I $_{5,774}$ & 2 I,6I6 \\
\hline France & $2,44 \mathrm{I}$ & 3,777 & 3,995 \\
\hline Italy & 2,078 & 2,263 & 2,772 \\
\hline Sweden & $\mathrm{I}, \mathrm{O} 74$ & 928 & I,046 \\
\hline Germany & 874 & $9^{22}$ & 674 \\
\hline Netherlands & 577 & 825 & $\mathrm{I}, \mathrm{I} 54$ \\
\hline Norway & 566 & 643 & 714 \\
\hline Denmark & $5^{2} 3$ & 624 & $5^{22}$ \\
\hline Switzerland & $49^{2}$ & 686 & 366 \\
\hline Canada & 232 & 2,222 & $2, \mathrm{I} 8 \mathrm{I}$ \\
\hline Spain & 93 & $\mathbf{I}, 497$ & $3,95^{I}$ \\
\hline
\end{tabular}

In this paper we will present a comparative analysis of some pertinent features pertaining to the understanding of kinship, that arise out of the practice of transnational adoption in Norway and Spain. We base our analysis upon national legislation and upon parental discourses of emotionality discernible in the kinning process. Norwegians began to adopt in the late r96os, but Spaniards did not start until the mid I990s. While the majority of Norwegians adopt because of involuntary childlessness, this motivates only half of the Spaniards. The other half adopt because they want another child, but are unwilling to do so through the 'normal' procedure. For a variety of reasons, these two countries have become prominent in the world of transnational adoption, adopting more children per capita than any other country. This 
is particularly interesting in light of their different cultural and political situations. Both countries adopt from abroad due to a paucity of native-born children being made available for adoption. The birth rate on its own may not account for this fact. Norway has one of the highest birth rates in Europe (I.85) and Spain, which had the highest birth rate in the EU in 1975 (2.8), now has one of the lowest (I.2). While the Norwegian birth rate continues to rise, the Spanish one remains low. However, we shall argue that both a high and a low birth rate give rise to cultural scripts that place a high value on parenthood. Involuntary childlessness is related to the age of first-time birth. This has increased from 28 in 1976 to $3 \mathrm{I}$ in 1997 in the Spanish case (the highest in Europe), and from 26 to 28.5 in Norway in the same period. As women get older, their fertility decreases and, by the time many decide that the time has come for them to become mothers, their biology does not co-operate.

While important, these facts explain little about the popularity of transnational adoption. In what follows, we shall look elsewhere in order to find further explanations for the practice. ${ }^{3}$ We start by briefly examining some pertinent sociocultural differences with regard to kinship, family values, and gender ideologies between the two countries. We then identify similarities and differences in the understandings, values, and practices of transnational adoption. We shall discuss how adoptive parents seek to symbolically negate the fact that their children are not their biological children. Because they come from countries whose populations have different genotypic features from those of their own, we examine how they reconcile these physiological differences. Our focus will be on concepts employed in the 'kinning process' (Howell 2003) and on the symbolizing of bodies and personalities in attempts to create meaningful resemblances between themselves and their children. The biological model of kinship is manifest in public debates and in relevant legislation in the two countries concerned, although we find several major differences in basic understandings and values. Norwegians have a reputation for a liberal attitude to sexual practice and politics. Spanish attitudes and practices in these regards are, in contrast, much more conservative. In view of these differences, it is surprising to discover that Norwegian legislation about adoption and new reproductive technology (NRT) is more restrictive than is the case in Spain. (We return to this below.)

Norwegian society may be characterized by a constitutive moral presence of the Protestant state religion, and has adhered to a welfare state ideology since the I93os. Spain, with a predominantly Catholic population, was, until

ETHNOS, VOL. 7I:3, SEPT. 2006 (PP. 293-3I6) 
I975, governed by a right-wing totalitarian regime. It was not until some years after having joined the European Union (in 1986) that Spain modernized economically, politically, and socially. While the Spanish economy today may be said to be comparable with that of Norway, socially and culturally many differences remain. This is particularly so when we examine matters that concern family politics, and the role played by women in society. We shall explore to what extent these differences affect legislation and attitudes to transnational adoption amongst the parties directly concerned. Our general conclusion is that while the laws differ markedly, the psychology of adoption appears to be little affected by the socio-cultural climate.

\section{Norwegian Family Life and Family Values}

In the r95os the ideal Norwegian family consisted of husband and wife and two to three children. This was a time when the status of the mother as housewife was at its peak. It was not until the I970s, with the rise of activist feminism, that changes were effected in gender relations, the labour market, and family life. Women entered the labour force in great numbers, and new welfare measures were introduced to facilitate the combination of motherhood, family life, and an outside career. Abortion on demand became legal in 1975 and contraception was made available to unmarried young people. At the same time, the social stigma attached to the unwed mother disappeared, and single women who wished to give birth received sufficient financial support to enable them to do so. State provisions for birth parents are amongst the most generous in the world (Ellingsæether \& Hedlund r998). As most men and women became actively employed in the work-force, family life became marked in new ways. Despite pursuing a career, women feel that to remain childless and not experience motherhood is an unacceptable deprivation, and more and more men are experiencing a similar sense of loss if they cannot experience fatherhood. These are amongst the factors that help to account for the continued high birth rate in Norway and for a lack of Norwegianborn babies being made available for adoption.

Thus, couples that remain childless despite their efforts to the contrary experience a sense of loss at a social as well as a personal level. The childless become outsiders to the life led by their contemporaries who, as children start to arrive, centre most of their free time on child-related activities. It is these childless couples who turn to alternative methods of procreation; in the first instance most try some kind of new reproductive technology and, if this fails, many turn to adoption. As virtually no child is given up for adoption,

ETHNOS, VOL. 7I:3, SEPT. 2006 (PP. 293-3I6) 
in effect to adopt means to adopt from abroad. Today, Norwegians adopt children from about 20 different countries. Despite a history of tolerant sexual politics, Norwegian laws are comparatively restrictive when it comes to laws regarding procreation. The rule is that only married couples will be considered eligible to adopt a child; neither cohabiting nor homosexual couples are allowed to adopt. Single women may, in special circumstances, be granted permission. The same restrictions apply to assisted conception. Moreover, only sperm donation from a known donor is permitted; neither egg donation nor surrogacy are allowed ${ }^{4}$ (Melhuus 2005). In these regards, Norway emerges as the most restrictive country in Europe. On the grounds that knowledge about biological origins is vital for the development of a balanced personality, Norwegian adoptees and children conceived by donor sperm may learn the identity of their biological parent(s) upon reaching the age of maturity. As we shall show, Spain has passed laws that enable more freedom of choice in these matters.

\section{Spanish Family Life and Family Values}

During and after the transition to democracy following the end of Franco's dictatorship in 1975, many changes have taken place in Spain that have affected reproduction and family life. The earlier influence of the Catholic Church weakened, thereby facilitating changes in family life and opportunities for women. However, in comparison with the situation in Norway, much remains to be done. The incorporation of women into the work-force is slow, salaries and conditions of work remain unequal and old stereotypes of gender relations remain fairly unchallenged. With a high youth unemployment and low salaries for young people, young people delay leaving their parental home, sometimes until their late thirties, by which time fertility is on the decline. At the same time, procreation is not a goal for many professional men and women, who see children as incompatible with their career development. Spanish husbands, unlike Norwegian ones, regard household and family matters as the sole responsibility of their wives while they remain the head of the family. A single woman at the age of eighteen is free to decide to take advantage of assisted reproduction technologies, whereas a married woman has to get authorization from her husband to do so.

Contraception was forbidden in Spain until I978. The first Divorce Act was approved in 1981. Although voluntary sterilization has become legal, abortion on demand is still not available. Proposals to make it so have several times been rejected. ${ }^{5}$ Four years after the birth of the first IvF baby in

ETHNOS, VOL. 7I:3, SEPT. 2006 (PP. 293-3I6) 
Barcelona in 1984 , the Assisted Reproduction Law was approved, and modified in 2003. According to Spanish laws, single persons (women and men) may adopt, as may homosexual couples (since April 2005). Single women and lesbian couples may receive assisted conception, and donor sperm and donor eggs are both allowed. Donation and 'adoption' of embryos are also allowed, but not surrogacy.

There are also differences in attitudes to the significance of biological origins. Spanish donor children and their mothers may ask for general information about the donors, but not for their identity. Donor identity may be revealed only in cases of serious risk for the child's life and/or health.

\section{Some Similarities and Differences in Values about Procreation between Norway and Spain}

Transnational adoption in Spain, as in Norway (Howell 2002; Marre \& Bestard 2004), began due to the decline in local children being given up for adoption. The years 1995 and 1996 saw the lowest birth rate in Spain, and mark the start of adoption from abroad. Many adoption associations link the beginning of international adoption in Spain to the repeated broadcasting at the end of 1995 of a series of British television programmes called The Rooms of Death from orphanages in China. The programmes showed the conditions to be abysmal, and many people in Spain (and elsewhere) reacted strongly, and felt a need to help by offering to adopt. The initial motivation was thus humanitarian as much as self-interested - although the practice conveniently coincided with the low birth rate.

Adoption in Norway similarly started as a humanitarian act, when abandoned children from South Korea and Vietnam arrived in the late I96os. However, today permission to adopt is normally granted only on the basis that one is unable to have children biologically. In recent years, most who choose to adopt have undergone unsuccessful medical treatment. Adoption and NRT are thus perceived as a single procreative universe of 'unnatural reproduction'. In Spain, on the other hand, this merging between the two practices is much less obvious. Involuntary childlessness is not a major motivation. In Catalonia, 47 percent of the families that applied to adopt in 2004 have biological children. For them, adoptive parenthood is simply an alternative way to have a child. As Marre was told by more than one adoptive mother who chose to adopt after having given birth to one or more children, 'I do not need to have my children through my body to feel them as mine.' While all Norwegian adoptive mothers would share the sentiment, few birth-moth-

ETHNOS, VOL. 7I:3, SEPT. 2006 (PP. 293-3I6) 
ers adopt a second or third child. This is an important difference between the two countries. Moreover, despite the fact that humanitarian motives are becoming frowned upon, many Spanish families mention the desire to help to poor and abandoned children as the main motivation. Yet another difference is that, due to the Spanish acceptance of homosexuals and single people to adopt, in Catalonia, single parents account for 16 percent of the adoption processes, and this is the group with the highest increase in 2004.

China is the main supplier of adoptees to both Spain and Norway, and both also receive many children from Colombia and Ethiopia (see note 2). While few children arrive in Norway from Russia and Eastern Europe and none from Morocco and Haiti - countries with fewer regulations - these are popular countries for Spaniards.

Prospective adoptive parents in both countries must undertake a lengthy and fairly thorough investigation of their personal situation by public authorities before permission is granted. This is a process that all find difficult, provoking, and which they characterize as prying. In fact, despite the more lenient formal criteria observable in Spain, this examination of individual applicants is not less stringent than that performed in Norway. Again, we find that Norway is more centrally organized and supervised. Adoption is carried out by one of three highly professional non-profitmaking NGOs that are licensed by the state and who have contact with orphanages and authorities in a number of countries. Applicants' suitability is vetted by them and by the local social services department, and final approval is granted by the state. Freedom of choice is strictly limited; only the birth country may be chosen and the parents may indicate a preferred age range. Sex or physiological characteristics, such as skin colour, may not be specified. Applicants may indicate if they are willing to accept a child with a 'minor disability'.

The procedure in Spain is decentralized to each autonomous community and each has its own practice. In Catalonia, prospective parents are evaluated by a private organization (ICIF) that is authorized by the state. A publicly run institution (ECAI) may undertake to help obtain a child, but their services are expensive. It is more common to approach one of many adoption associations which are run by parents who have adopted children from a particular country. To all intents and purposes, they have become adoption agencies, but as in Norway, final approval is granted by the state. Depending upon the rules of the donor country, Spanish adopters, unlike their Norwegian counterparts, may be very selective of their child. Indeed, in some donor countries, such as the Ukraine and Haiti, parents travel to

ETHNOS, VOL. 7I:3, SEPT. 2006 (PP. 293-3I6) 
the country before being allocated a child, and are given a choice amongst all children available for adoption. Elsewhere, Spanish applicants may state their preferred age range and sex.

From observable differences in gender and family life practices, one might expect corresponding differences in official attitudes to adoption. This is not so. Not only does 'conservative' Spain give much more freedom of choice to its citizens in its legislation than 'liberal' Norway, but there is an observable misfit between the values of the legislators and the public in both countries. Spanish social life continues to be marked by traditional family values while Norwegian social life has undergone nothing short of a revolution in these matters. However, we witness a liberal legislation in matters of procreation in Spain; granting equal rights to all regardless of marital status, and freedom of choice regarding method of procreation. We also note that Spanish law is less concerned with biology as a basis for meaningful relatedness in that anonymity of biological origin is maintained. Norwegian law, on the other hand, having abandoned the anonymity clause, arguably defines 'true' kinship on biogenetic grounds. Adoptive parents in both countries have no problem with accepting the adoptive relationship as a real kin relationship. Norwegian law further protects the heterosexual family by restricting adoption and assisted conception to legally married couples and denying egg donations. These restrictions do not enjoy the support of the majority population (Howell \& Melhuus forthcoming). Despite Spanish legal provisions that allow adoption by single people and homosexuals, many Spanish experts, and the public at large, wish to see that adoptive families conform to traditional family patterns (Salazar, personal communication). One possible explanation for these, on the face of it, surprising findings may be traced to the role of religion in the two countries. Norway has a state church with a very influential voice in matters that pertain to the moral sphere. They are profoundly sceptical to all interference in 'the natural order of things' of family and procreation. The Norwegian government for the past eight years was led by an ordained priest who was the head of the Christian Democrat Party. This accounts to a large extent for the restrictive legislation passed during that period; a legislation that was at odds with the views of the majority. In Spain, while the Catholic Church is still influential, it has no official say in politics and the legislative processes. The Spanish government has been led by Social Democrats since the end of the 'Transition' and has been keen to 'modernize' Spanish social life. This helps explain the permissive nature of Spanish legislation on family and procreation, legislation that

ETHNOS, VOL. 7I:3, SEPT. 2006 (PP. 293-3I6) 
does not necessarily reflect majority opinion. An amusing event of relevance took place while we were revising this paper. A headline in the largest Norwegian daily paper reads, 'To Catholic Spain to learn about homo-politics'. Following the elections in the autumn of 2005 , a socialist coalition came to power in Norway on a platform of liberalizing laws dealing with family matters. Although homosexual couples were allowed to enter into legal partnership in 1993, this entailed fewer rights than a marriage, and has been a bone of contention ever since. According to the deputy minister for family affairs who is heading the visit to Spain, they go in order to learn about the Spanish marriage law that makes no distinction according to the sex of the partners. 'Spain was one of the first countries to have passed a single marriage law', he states, 'and this is particularly interesting given that Spain is a Catholic country' (Aftenposten 4 April 2006:3).

\section{Parental Attitudes to the Reality of a Kin Relationship}

What is remarkable about Norway and Spain is that, despite the numerous differences in socio-cultural conditions, and in the motivations of those who seek to adopt, there is a high degree of similarity in adoptive parents' attitudes with regard to their adopted children and in the kind of discursive practices that they engage in. The similarity of reactions of prospective parents when informed that a child has been allocated them is striking, as is the way they employ an idiom of resemblances between themselves and their children. Overarching these, and other kinning devices, is a scenario of fate, or destiny. Parents in both Norway and Spain again and again express the idea that their child was meant for them in some mysterious way. No other child would have done as well. This is exemplified by the following example of two Norwegian mothers who adopted children from China at the same time. One mother said laughingly to the other, 'Just image if Ida had been given to you and Maria to me. I wonder how that would have worked out.' 'Oh, dear me, no', said the other, shocked, 'that would not have worked out at all. Ida would not have suited you. She is so like us, but not in the least like you. No, that would have been quite impossible. Ida was really meant for us. She fits in so well. And it is clear to everyone that Maria could not be anybody else's child but yours'. We return to a discussion of this scenario of fate below. What has to be borne in mind is that by the time they are allocated a specific child, the awaiting parents have gone through a long period of waiting and longing and of preparing themselves for the event of becoming parents and a family. The period may be subdivided into three stages, the pre-pregnancy, pregnancy

ETHNOS, VOL. 7I:3, SEPT. 2006 (PP. 293-3I6) 
and the birthing stages. With the exception of the first, these terms are used by adoption agencies and adoptive parents (Howell 200I, 2003).

\section{(i) Pre-pregnancy}

By the pre-pregnancy stage, we mean the period that starts when a couple (in Norway) or a couple or an individual (in Spain) decides to adopt a child from abroad. Most experience this as a stressful time, a period of uncertainty before they are approved (or rejected) by the relevant public authorities. It is a period which is filled with longing, desire and insecurity about the outcome, but never doubt about the wished-for outcome.

People begin the process by selecting a country. Criteria may be personal attachment, racial (not allowed to be specified in either country, see below) or geographical or cultural proximity. The choice may result from some earlier affinity with the country in question, or it may be due to practical criteria such as the likelihood of the baby being young, the speed of the transaction, and one's age and marital status. Once a country is selected, prospective parents start to build an emotional bond with the country, and they start to imagine the kind of child they will eventually have. To have to change the country is thought to be particularly emotionally difficult. A Spanish mother-to-be of a Chinese girl said that for her it would be a great shock to have to change the country because, once she decided where to adopt, she started to imagine her daughter. Another mother who, due to procedural problems in her application in Brazil, had to adopt in the Ukraine, recalled the change as the worst moment of the process, something that discouraged her from considering another adoption. A mother with one biological child decided to adopt her second. She explained her choice to adopt in Morocco in terms of geographical and cultural proximity and bureaucratic obstacles in the following terms:

We were looking through the files and, well, one has one's preferences, likes and dislikes, and we decided we were not interested in anything concerning Russia, Ukraine, Romania or China. I don't know, we don't know those cultures. Latin America was another possibility... but there were several drawbacks, such as in some countries you had to stay for two months, which we could not do... The advantage was the language, of course, but at that moment... in some Latin-American countries some files had been held up for 4 or 5 years. Well, we decided to pass on that. There was India, also, but there were other problems. In many orphanages in India you have to have been married in the Church to adopt because they are run by religious staff, and we thought our file would be held up

ETHNOS, VOL. 7I:3, SEPT. 2006 (PP. 293-3I6) 
there. Then, our first idea was Africa, not Morocco, but Africa. But [that meant] Madagascar, which was also an ordeal, because when you were there filling out the forms - I think it has now changed - you had to travel to South Africa on several occasions, because it somehow belongs to South Africa for some matters. So then we said, well, Morocco.

\section{(ii) Pregnancy}

Pregnancy, we suggest, starts when the applicants receive the approval from the public authorities and an application is sent to the country. At this point the applicants know that they will become parents, but they do not know how long it will take. This is a period during which the applicants in both Norway and Spain prepare themselves mentally, emotionally and practically to become parents to a child born by unknown others in a foreign country who, moreover, will look quite different from themselves and the majority of the population of which they are a part. As such it is a challenging pregnancy. Just like people expecting a biological child, adoptive parents now prepare their surroundings for the forthcoming event. To many, it is the fact of looking different that takes on significance. In Spain, where the practice is relatively less established, the fact that they neither have a nine-month pregnancy, nor look pregnant, means that adoptive parents have to explain their 'pregnancy' in order to make it visible and acceptable.

Having chosen a donor country, many adoptive parents make contact with others who are adopting, or have adopted, from the same country. During this time the country associations (in Spain), and the adoption agencies (in Norway), encourage families to find out about the child's country of origin. They arrange special classes for adoptive parents in which they are prepared for the task ahead, and told that while theirs is an abnormal pregnancy and birth, it is no less real for that. They are warned that, although they will love their child just like biological parents do, the rest of the world may not accept the relationship and the child may experience being ostracized and the object of racism. The pregnant couple further performs the usual tasks of others in the same situation. They start to plan the child's room, they think about their future in new terms

\section{(iii) Birthing}

The birth begins when expecting parent(s) receive information that a particular child has been allocated them, and is completed upon the child being handed over. This is a momentous occasion that adoptive parents, regardless of nationality, describe in similar ways. It starts with the call from

ETHNOS, VOL. 7I:3, SEPT. 2006 (PP. 293-3I6) 
the adoption agency telling them that they have become parents. They are given some details as to sex, name, approximate age, health condition, and some of the child's early history - if known. Most parents receive the news with untempered joy, and experience it as a moment of personal destiny, experiencing an immediate bond between themselves and their child-to-be. The following description by a Norwegian mother of a boy born in India is typical: 'they told me that I had become the mother to a tiny boy and Lars had become the father. From that telephone conversation it was exactly that boy, Shavran, who was our boy. We had not seen him, not even a photo, not held him, but I felt so strongly that it was precisely him' (Karlsen 2002:I5). Norwegian parents are given a day to decide if they will accept the child they are offered. Virtually none refuse. They feel that this child is somehow meant for them, that to refuse it would be to deny the element of destiny and to differentiate their birth from that of biological birth. 'A woman who gives birth to a child has to accept that child', Howell was told, 'therefore we must accept whatever child is given us'. The photograph of the allocated adopted child is duplicated and distributed to friends and family. The preparatory work to receive the child is now engaged in with renewed efforts. This is the moment when the seeds of what will be a permanent relationship are planted. A Norwegian couple whose allocated infant daughter died before they could collect her were grief-stricken, and arranged for a memorial service in their local church to which family and friends were invited (Adopsjonsforum).

Adoptive parents everywhere are prone to magical thinking. Sometimes, a sense of predestination may be provoked by the coincidence of a name, or a date. Many adoptive parents that we have interviewed refer in some way or other to such coincidences. A mother who was waiting to collect her daughter in Haiti said that she thought that she would have some news on 20 February. She spent that day checking her e-mail every fifteen minutes, but none arrived. However, she was delighted when later she learned that the girl she had been assigned was born on 20 February. Another woman whose child came from Morocco was told that the allocated child was born on the day that she submitted her application. The mother of a child found on a rail-way line in Korea said that this meant that the child was meant to travel.

Adoptive parents thus activate a meaningful discourse of belonging through, we suggest, a discourse of destiny. There are many examples of people who, having specified a preference for sex or age, are offered a child of different sex or age. Most accept the child. Destiny appears to override previous ex-

ETHNOS, VOL. 7I:3, SEPT. 2006 (PP. 293-3I6) 
pectations. When a Spanish adoptive couple who had asked for one child between the ages of o and 3 was asked if they would accept three siblings of 9 months, 18 months, and 3 years of age, they accepted. A homosexual couple (adopting as single) had asked for a girl between $\mathrm{o}$ and 3 , but accepted a girl who was ro years old.

While Norwegian applicants may not choose their child, but have to wait and see who they are offered, Spanish associations have arrangements with some countries, like Haiti, Morocco, and the Ukraine, where the selection is made by the parents themselves at the orphanage. In the Ukraine, they have to go to different orphanages in order to make their choice. For some families, the selection process can be quite traumatic and may cause postadoption depressions (Núñez 2004). Others take it as something that is part of the adoption process itself. This is how a mother told about selecting her son at an orphanage in Morocco: 'well, they're there... in class... And they show you those that are in the age range that you had asked for... My husband immediately noticed Am, who was precisely the one who was not paying attention, the one who was doing nothing and was sort of hidden... My husband had worked with mentally-challenged children for years and he clearly saw that the boy had no problem, though I thought there was something wrong with him... but my husband told me that the child had no problem, and I told him I trusted him. And, of course, the boy has no problem whatsoever.'

Today, most adoptive parents choose to go and collect their child themselves. They feel a need to see for themselves what the country is like, the conditions of the orphanage where the child has been living, and, in the case of Spanish parents adopting from Haiti, to meet, if possible, biological relatives. Having accompanied a group of seven Norwegian couples on their trip to Ethiopia to collect their child, Howell was impressed, and moved, to witness the strength of the unqualified love expressed by the parents and the immediacy of the bonding that occurred between them and their child. The parents were totally absorbed with their new son or daughter who responded with alacrity.

It is clear from our researches that the moment of allocation of a child and the actual first meeting with that child are momentous for the parents. They have waited so long for the event to take place, they have longed to become mothers and fathers, they have envisaged with anticipation life as a family, that when a child is identified as theirs, there is no doubt in their minds that this is the right child. From that moment they never look back. 'Adoption

ETHNOS, VOL. 7I:3, SEPT. 2006 (PP. 293-3I6) 
is the natural way for us to have children', said a Norwegian father of three adopted children from Colombia.

\section{The Quest for Resemblances}

In European and North American understanding it is assumed that children take after their parents, or other biological relatives, in a variety of ways. Such an understanding is based on a notion of shared blood and shared flesh. People look for some common physiological resemblance between a child and his or her close kin, or children are said to display a certain gift (e.g., for music, painting, dance, mathematics) that can be traced to a parent or grand-parent. Or, again, they may display a personality trait that 'runs in the family', such as a quick temper, generosity, absent-mindedness. Likeness between biological kin confirms the reality of relatedness. In line with this thinking, medical staff at fertility clinics look for resemblances between a sperm or egg donor and the intended parents. In Norway (where only donor sperm is allowed) the medical staff take care in trying to match the donor's physical make-up with that of one or other of the receiving parents. This is the same in Spain where the Assisted Reproduction Law makes matching a medical staff responsibility.

No such matching is possible between European adoptive parents and their adopted children from Asia, Africa, or Latin America. Most transnationally adopted children cannot be mistaken for their parents' biological children. However, as mentioned, this does not prevent parents from creating narratives of resemblance. Once fate has given one a child, it is not a big step to search for characteristics that resemble one's own. A father who collected his 6-month-old son in Ethiopia responded to Howell's comment that the boy looked well and quite sturdy, by saying that this was no surprise given his own sturdy physique. At the same time, others may assist the adoptive parents in this quest towards naturalization. A female friend of a Norwegian adoptive mother told her, quite spontaneously, how her adopted daughter from Korea had just the same hot-tempered personality as her. The mother expressed pleasure at the comment; it demonstrated to her how the world at large accepted the relationship as a mother-daughter one.

The photograph of the allocated child that is circulated is commented upon by relatives and friends who look for some common feature. 'She has such a lovely smile, just like yours', or 'look, his curls are just as wild as yours', and so on. A Spanish woman who adopted in Haiti told about her mother's reaction upon receiving a photo of her new granddaughter: 'My old 
woman was phoning me up every ten minutes the whole afternoon. I think she would look at the photo and phone me again. And she told me "this girl looks exactly like you. Yes, this is how you looked when you were a child".' By searching for similarities and resemblances, adoptive parents - and their relatives and friends - naturalize the relationship.

Most families know roughly what their adopted children will look like once they have chosen a country. However, nothing is absolutely certain. This was demonstrated by the case of a Spanish family adopting in Russia who, when they went to collect the assigned girl and saw that she was not Caucasian, but had Mongol features, rejected her on racial grounds. They said that they needed a physical resemblance with the baby in order to identify themselves as parents. This is an unusual case, but it illustrates a felt need to experience some kind of a resemblance between themselves and their adopted child even though, to the outsider, this seems far-fetched.

\section{The Matching of Adoptees with Parents}

This emphasis on family likeness in the discursive kinship practice of European countries may further contribute to a prevailing, unsubstantiated, fantasy in the world of adoptive parents that staff in orphanages, or local administrators, spend much time and effort in trying to match the applying parents with a particular child. Such notions remove any idea of pure randomness in the origin of the relationship. Perhaps it compensates for the absence of shared genes? Spanish adoptive parents are particularly committed to such a scenario. The posited activities of the so-called Matching Room at the China Centre of Adoption Affairs (CCAA) in Beijing, through which all Chinese children are allocated, is widely held to be true (Marre \& Bestard forthcoming). Here, the story goes, the employees examine the dossier and the photograph of every submitted child and the dossier and photographs of every applicant in order to identify some similarities that would make the allocation a particularly suitable one. They may look for physiological features that are similar in some way, or personality traits. Musicality is always the one example that is brought up.

Norwegian parents harbour similar notions that staff in the donor country try to match the child they have been given with themselves, but they seem less concerned with this than Spanish couples. This may be because transnational adoption in Norway has been practised for much longer, and in the early days of adoption such notions were not on the agenda. At that time people often adopted out of a desire to help an orphaned or abandoned child

ETHNOS, VOL. 7I:3, SEPT. 2006 (PP. 293-3I6) 
as much as to get a child of their own. Although the motivation has changed, and today Norwegians adopt in order to obtain the child they themselves are unable to produce, notions of matching are not elaborated. Norwegian applicants seem to liken the event more to that of biological birth, and hence to chance, than do Spanish couples. This is not to say that once a child has arrived, as we saw above, Norwegian parents do not look for resemblances between themselves and their child.

Although there is, indeed, a Matching Room at CCAA, Norwegian adoption workers are highly dubious as to what goes on inside it. They think that its existence is most likely a response to demands from North American and European adoption agencies - reflecting the expectations of their customers. Even if they had an ambition to do something like that, how could they possibly examine the more than Io,ooo adoptions that are transacted every year in China? Furthermore, as most Chinese infants are abandoned anonymously and as small babies, there are few clues as to their characteristics and abilities. Allocation in most countries is done on a strict rota system.

The point is not whether this kind of matching work takes place or not in China - or elsewhere - but that Spanish couples in particular, and Norwegian ones to a lesser extent, feel a need for this to be so. The desire for the existence of a matching room such as the one in Beijing is in itself an interesting fact. When they embark upon the process of adopting a child from an alien country, prospective parents activate a biological model by employing terms like pregnancy and birth. They further deny absolute chance by insisting that their child and they are not only mysteriously destined for each other, but that the selection is the result of a deliberate choice. Resemblances between themselves and their adopted child, whether in the form of physiological or psychological characteristics or special gifts, are sought and rendered relevant. The notion of fate remains, just as ultimately it does in biological birth, and pure chance is eliminated.

\section{Sameness and Difference}

What we can learn from these examples - and numerous others of the same kind - is that parents of transnationally adopted children share a desire to negate the patent differences that exist between themselves and the children that they have adopted from a distant country, and that one way of doing this is to engage in a discourse of fate and destiny with regard to why precisely that child became my/our child, and to establish some kind of resemblance between themselves and their adopted children. Like parents 
everywhere - whether biological or adoptive - they engage in a kinning process of the child from the moment of confirmed pregnancy. The aim is to incorporate the child into their kin group, and one way to achieve this is by talking about the child in a recognizable kin idiom. Kinning during biological pregnancy presents few difficulties. It is only when procreation itself represents a rupture with established practice that problems arise for those concerned. Transnational adoption in Europe and North America is such a rupture. It is a double rupture when the child's physiognomy is different and when it comes from a distant land. An imagined sameness has to be created for the child to become part of the imagined community of his or her new family, kin and nation.

As the transnationally adopted children do not, in the vast majority of cases, look like their parents, they represent an enigma to the ignorant outside eye, a challenge to the normal order of things. Their very presence in their familial setting demands an explanation. As far as the parents are concerned they are a family as real as any other; they do not feel a need to legitimize the relationship. But the kinning process for them seems to require an extra dimension, namely the deliberate inclusion of the adopted child into their own personal domain of resemblances. The adoptee has, somehow to be acknowledged as 'the same'. This is achieved, both in Spain and Norway, by identifying aspects of bodily, intellectual, or emotional resemblances between the child and themselves. It is a quest engaged in for personal satisfaction, but with wider social implications. In the words of a woman who had both a biological and an adopted child, 'biological maternity is easier; the adoptive one has to work harder. Biological maternity makes you grow emotionally, perhaps, but adoptive maternity makes you grow humanly.'

At the same time, patent differences cannot be ignored. In fact, in certain contexts they are marked. The two most obvious example of marking difference can be found, firstly, in the associations that exist for families whose children have been adopted from the same country, and secondly, in the growing popularity of so-called return visits that families undertake to the adoptees' country of origin (Howell 2003, 2006; Marre 2004). In Norway, country-based associations have existed for many years. In the many local and national branches they arrange social events and big annual national gettogethers. While parents maintain that they participate in the social events for the sake of their children - so that they may meet others like themselves - Howell argues that they participate as much for their own satisfaction (Howell 2002). A similar rationale for social activities based on country of

ETHNOS, VOL. 7I:3, SEPT. 2006 (PP. 293-3I6) 
origin is encountered in Spain. 'It's for your son, so that he doesn't feel that he is the only one, and will know that there are others like him', a father told Marre (Marre 2003). However, Spanish informants often gave another reason for the country-based associations. According to one, 'you belong to the country your children belong to ... your children are from there, you have links with that country, little by little you know those people, you get used to them...' (Marre 2003). Adoptive parents everywhere take an interest in the culture of the country (Yngvesson 2002), but in most cases this interest does not go beyond that of an averagely informed tourist.

However, Spanish adoptive parents seem to engage more actively with the country of their children's origin than do Norwegians. This greater interest may be because Spain began to adopt at a time when transnational adoption discourses began to emphasize questions of roots, and the need to encourage a child to accept his or her 'two cultures'. The notion of 'two cultures' has been prevalent for some years in Norway also, and there is a growing trend for Norwegian adoptive parents to take their child on a visit to his or her country of birth. We suggest that to engage actively with the children's country of origin has another purpose as well, namely to reduce the 'ghost' of the unknown content of the children's 'backpack' that they are understood to carry with them on arrival; backpacks filled with experiences and impressions from their life before arriving at their adoptive parents... (Howell 2004; Marre 2004, forthcoming). 'It is important not only to know where your child comes from, but also to know his reality', a Spanish adoptive father said. When they collect their children, parents try to obtain as many details as possible. They try to build a story about the child's early life so that they can tell him/her later. As a response to this need, some orphanages provide each child with a 'life book' which gives details about their life at the orphanage.

Increasingly, adoptive parents take it for granted that their children will wish to see the country from which they came. According to one Spanish father, 'sooner or later, your children will ask you to take them to their country of origin so as to get to know their own origins. Adolescence implies a construction of identity and Judith, who is ten years old, is at its doors. I prefer to anticipate it instead of coming too late. Therefore, we've already decided where to go for the 2005 vacations: Zipaquirá.' Some Spanish prospective parents choose a country close to Spain, such as Morocco, for the explicit reason that to travel there would not be difficult. Howell argues that the majority of adopted children are much less interested in such return visits than are their parents (Howell 2002).

ETHNOS, VOL. 7I:3, SEPT. 2006 (PP. 293-3I6) 


\section{The Transnationally Adopted Child - An Immigrant?}

In Spain, as in Norway and the rest of Europe, two parallel phenomena are happening that bear some relation to each other and to the topic of this paper. Immigration from outside Western Europe and international adoptions are both increasing in volume. Broadly speaking, immigrants and adopted children come from the same regions: the poor South and the former Soviet Union. Both phenomena have become socially relevant during the past thirty years in Norway and from the second half of the I99os in Spain. They are, however, viewed very differently.

In both Norway and Spain, the laws, and general attitudes, regarding non-Western immigrants and adoptees differ enormously. Whereas attitudes regarding immigrants are becoming more and more negative, there is a positive attitude towards children being adopted from the same countries; immigration laws are becoming more restrictive, while adoption laws show a tendency to become more open. This would indicate a clear dichotomy in thinking that shows that the concept 'immigrant' does not constitute a single category. Rather, those immigrants who become incorporated into a native family, kinned and 'transubstantiated' (i.e., adoptees, Howell 2003), are viewed by the authorities (and the rest of the native population) as quite a different category from those who arrive in order to find work or as asylum seekers - despite the fact that from a physiognomic point of view they are indistinguishable (Howell \& Melhuus forthcoming; Marre 2005).

The term immigrant has become racially coded (Wade 2002), and despite an absence of the term 'race' in public discourse, signs of racism may increasingly be observed in both countries. In fact, culture is becoming a euphemism for race, as in 'multi-cultural', and some argue that cultural fundamentalism is on the increase in Europe (Stolcke 1995). Although the multicultural society is perceived as highly problematic and has become a national concern, transnational adoption is not. Rather, transnational adoption is not normally talked about as immigration, and Norwegian adult adoptees deny that they are immigrants. They are supported in this by the population at large. In Spain, where class differences are more marked than in Norway, the distinction between immigrants and transnationally adopted children is very clear. A school teacher from an upper class suburb in Madrid told Marre, 'We do not have immigrant children [in the school], we have children adopted internationally'. In the early days of transnational adoption in Norway, children who looked 'different' were assumed to be adopted and treated well. As the influx of immigrants has increased (today 29 percent of children in primary

ETHNOS, VOL. 7I:3, SEPT. 2006 (PP. 293-3I6) 
schools in Oslo are of 'immigrant background') the issue is more complicated. Nevertheless, by telling strangers that they are adopted, most adoptees experience an atmosphere of inclusion. For race to be an issue - however muted - it would appear that the acid test may be traced to the degree and kind of significant relatedness of the individuals concerned. While the adoptees, by and large, are included in Norwegian and Spanish kinned sociality and culture, at the expense of their place of birth (Howell 2003), the immigrants continue to look to their own kin, culture and place of origin in order to establish and confirm their identity. This shows how kinship is of the highest significance in matters of identity, belonging, ethnicity, and nationhood.

\section{To Conclude}

The practice of transnational adoption is here to stay, and in the foreseeable future is likely to increase. In countries where a biologization of discourses of identity is increasing and where undesired immigration continues, adoptive families have a problem. We have observed some contradictions in adoptive parents' attitudes to the relationship between themselves and their transnationally adopted children. On the one hand, they engage in activities to kin their child; in discursive practices that emphasize fate and the ensuing resemblances between the child and themselves. On the other hand, in certain contexts, they insist on emphasizing the differences between their children's national, cultural and - to a lesser extent - biological origin and their own. Despite social and political difference between Norway and Spain, we find when we examine the meaning of transnational adoption on a personal level, a remarkable number of similarities in values, emotions and attitudes of the adoptive parents. This is especially striking given the differences in the motivation to adopt in the two countries, and the many socio-cultural differences that exist. As adoption in Norway is primarily undertaken by people who are involuntarily childless and whose driving force is to become a 'normal family', we should, perhaps, not be surprised by the vehemence and single-mindedness with which they engage in the process of obtaining and kinning their children. However, adoption in Spain is undertaken in equal numbers by involuntarily childless and people who desire a second or third child, but who will not, for a variety of reasons, do so the natural way. In the latter case, one might expect a somewhat less intense emotionality. But this does not seem to be the case. We find that prospective adoptive parents in both countries, regardless of motivation, forge an immediate bond with the child who has been chosen for them, and that they do so within a discourse

ETHNOS, VOL. 7I:3, SEPT. 2006 (PP. 293-3I6) 
of fate. We further find that adoptive parents embark upon a path of actively kinning their allocated child and that they employ methods employed by biological parents, such as looking for resemblances, a task that in many cases requires both imagination and fortitude.

\section{Acknowledgments}

Howell and Marre both participated in the EU-funded project Public Understanding of Genetics: A Cross-cultural and Ethnographic Study of the New Genetics' (2002-2004) under Framework 5, the Quality of Life and Management of Living Resources Programme; contract number QLG7-CT-200I-oI668. Howell has also received support from the Norwegian Research Council and Marre from the Spanish Ministry of Science and Technology (BSO2003-06I48). An earlier version of this paper was presented at the conference 'Contemporary Perspectives on Kinship in Europe' at Maison des Sciences de l'Homme, Paris, November 2005. We are grateful to Enric Porqueres and Marit Melhuus for inviting us.

\section{Notes}

I. The background to this paper lies in the fact that the authors participated in the EU-funded research project Public Understanding of Genetics and Family in Europe. Howell had been studying transnational adoption in Norway sine 1999 and, because of the sudden growth of the practice in Catalonia and Spain, Marre decided to change her focus from fertility clinics to adoption. From the start we were intrigued by similarities and differences in values and practices and decided that the material called for some comparative analysis.

2. Table 2a: Numbers of adoptees from major donor countries 1980-89, 1995, 1998 (to ten receiving countries) (Source Selman 2000).

\begin{tabular}{|lrlrll|}
\hline I980-88 & & I995 & & I998 & \\
Korea & 6,I23 & China & 2,559 & Russia & 5.064 \\
India & I,532 & Korea & 2,I45 & China & 4,855 \\
Colombia & I,484 & Russia & 2,0I4 & Vietnam & 2,375 \\
Brazil & 753 & Vietnam & I,249 & Korea & 2,294 \\
Sri Lanka & 682 & Colombia & I,249 & Colombia & I,I62 \\
Chile & 524 & India & 970 & Guatemala & I,I43 \\
Philippines & $5 \mathbf{I 7}$ & Brazil & 627 & India & I,048 \\
\hline
\end{tabular}

Table 2b: Number of adoptees from major donor countries in 2003

\begin{tabular}{|lrlr|}
\hline China & Io,OI5 & Kazakhstan $・$ & 825 \\
Russia & $7,5 \circ 3$ & Colombia \# & I,40I \\
Guatemala & 2,328 & Bulgaria \# & $74 \mathbf{I}$ \\
South Korea & I,790 & Haiti \# & 652 \\
Ukraine & I,929 & Ethiopia \# & 593 \\
India & 942 & & \\
\hline
\end{tabular}

- Figures for USA only

\# Figures for Europe only (Source Selman 2005)

ETHNOS, VOL. 7I:3, SEPT. 2006 (PP. 293-3I6) 
Table 3: Number of adoptees from major donor countries to Norway in 2004

\begin{tabular}{|lr|}
\hline China & 269 \\
South Korea & 93 \\
Colombia & 86 \\
Ethiopia & 47 \\
Philippines & 33 \\
Thailand & $3^{\mathbf{I}}$ \\
India & 27 \\
Russia & I2 \\
Brazil & I I \\
Hungary & IO \\
\hline
\end{tabular}

Table 4: Number of adoptees from major donor countries to Spain and Catalonia in 2004

\begin{tabular}{|lrr|}
\hline & Spain & Catalonia \\
China & 2,389 & 688 \\
Russia & I,6I8 & 506 \\
Ukraine & 349 & 55 \\
Colombia & 256 & 38 \\
Ethiopia & 220 & 87 \\
India & II 7 & I3 \\
Bolivia & 92 & 6 \\
Nepal & 68 & 53 \\
Bulgaria & 57 & 6 \\
Peru & 50 & 0 \\
Romania & 48 & n/d \\
Haiti & 36 & I I \\
Kazakhstan ** & 24 & 2 \\
Dominican Rep. & 24 & 2 \\
El Salvador & 22 & 4 \\
Morocco * & 2I & 2I \\
\hline
\end{tabular}

* In 2002 only I and 7 children were adopted in Haiti and Morocco respectively.

** Just one child was adopted in 2003 .

3. Our researches have been both multi-sited and wide-ranging. Both Howell and Marre have undertaken participant observation in a local adoption agency, interviewed a great number of adoptive couples formally and informally, and read and participated in several Internet chat groups. They have paid close attention to media coverage of transnational adoption and talked to a number of professional personnel involved in the activity. Howell has participated in preparatory courses for adoptive parents, in a return visit to Korea with a group of adoptive families, and accompanied a group of parents to collect their children from Ethiopia. Both authors have been invited to talk about their research to various interest groups - both adoptive parents and professional bodies. Their reactions have been put back into the analysis. 
4. Some of this may change in the near future. The general election in autumn 2005 resulted in a left coalition government, whose programmes have included a more open attitude to the criteria for adoption. So far (February 2006), no concrete proposals have been made.

6. Abortion may only be performed if the health of the woman or the foetus is in danger or if the pregnancy is the result of rape.

\section{References}

Ellingsæter, Anne-Lise \& Mary-Ann Hedlund. 1998. Care Resources, Employment and Gender Equality in Norway. Oslo: Institutt for Samfunnsforskning.

Howell, Signe. 200I. Self-Conscious Kinship: Some Contested Values in Norwegian Transnational Adoption. In Relative Values: Reconfiguring Kinship Studies, edited by Sarah Franklin \& Susan McKinnon, pp. 203-223. Durham: Duke University Press.

- 2002. Community Beyond Place: Adoptive Families in Norway. In Realizing Community: Concepts, Social Relationships and Sentiments, edited by Vered Amit, pp. 84I 4. London/New York: Routledge.

-. 2003. Kinning: the Creation of Life Trajectories in Transnational Adoptive Families. Journal of the Royal Anthropological Institute, (N.S.) 9:465-484.

-. 2004. The Backpackers that Come to Stay: New Challenges to Norwegian Transnational Adoptive Families. In Cross-Cultural Approaches to Adoption, edited by Fiona Bowie, pp. 227-24I. London/New York: Routledge.

- 2006. The Kinning of Foreigners: Transnational Adoption in a Global Perspective. Oxford/New York: Berghahn Books.

Howell, Signe \& Marit Melhuus. Forthcoming. Mixed-race Families - Do They Exist? Some Criteria for Identity and Belonging in Contemporary Norway. In Race, Ethnicity and Nation in Europe: Perspectives from Kinship and Genetics, edited by Peter Wade. London/New York: Berghahn Books.

Karlsen, Kari Beheim. 2002. Arve - Sonen Min. Oslo: Gyldendal.

Marre, Diana. 2003. Associations for the Infertility Treatments and Associations for Transnational Adoptions: The Civil Society Organisation around New Themes, http:/les.man.ac.uk/sa/pug/intrdoc/intr7.htm.

- 2004. La adopción internacional y las asociaciones de padres adoptivos: un ejemplo de sociedad civil virtual global. In Scripta Nova. Revista electonica de Geografia y Ciencias Sociales, VIII, I7o. Barcelona..

-. 2005. Intercultural Relations, Racialisation and Experiences of International Adoption in Europe: The Spanish Case. Paper presented to the wellchi Network: Workshop 4: 'Children in multicultural societies', Athens.

- . forthcoming. 'I want her to learn her language and maintain her culture' Transnational adoptive families' views on 'cultural origins'. In Race, Ethnicity and Nation in Europe: Perspectives from Kinship and Genetics, edited by Peter Wade. London/New York: Bergham Books.

Marre, Diana \& Joan Bestard. 2004. Sobre la adopción internacional y otras formas de constituir familias: a modo de introducción. In La adopción y el acogimiento: presente y perspectivas, edited by Diana Marre \& Joan Bestard, pp. 17-72. Barcelona: Universidad de Barcelona.

—. forthcoming. The Family Body: Persons, Bodies and Resemblances, edited by Jeanette Edwards \& Carlos Salazar.

ETHNOS, VOL. 7I:3, SEPT. 2006 (PP. 293-3I6) 
Melhuus, Marit. 2005. Better Safe than Sorry: Legislating Assisted Conception in Norway. In State Formations, edited by Christian Krohn-Hansen \& K.G. Nustad, pp. 2I2-233. London: Pluto Press.

Núñez, Cristina. 2004. La depresión post-adopción. In La adopción: Aspectos psicológicos implicados en la filiación adoptiva, edited by C.E.A. Alda, pp. 7-I4. Barcelona: Collegi Oficial de Psicòlegs de Catalunya.

Selman, Peter. 2000. Intercountry Adoption: Developments, Trends and Perspectives. London: British Agencies for Adoption and Fostering.

-. 2005. Trends in Intercountry Adoption 1998-2003. School of Geography, Politics and Sociology, University of Newcastle.

Stolcke, Verena. I995. Talking Culture: New Boundaries, New Rhetorics of Exclusion in Europe. Current Anthropology, 36(I):I-23.

Strathern, Marilyn. 1992. After Nature: English Kinship in the Late Twentieth Century. Cambridge: Cambridge University Press.

Wade, Peter. 2002. Race, Nature and Culture. London: Pluto Press.

Yngvesson, Barbara. 2002. Placing the 'Gift Child' in Transnational Adoption'. Law E' Society Review, 36(2):227-256. 